\title{
Is There a Pragmatist Approach to Literature?
}

\author{
Giles GuNN \\ University of California, Santa Barbara, USA \\ Program in Global and International Studies \\ ggunn@global.ucsb.edu
}

\begin{abstract}
This article explores the relation between literature as a form of artistic understanding and pragmatism as a form of philosophical inquiry. It does so, first, by exploring the place that each similarly accords the imagination as an instrument both of knowing and of making. The American philosopher John Dewey expressed the nature of this linkage when he argued that the purpose of art - and, he could have added, of pragmatic reflection as well - is to contrast actual conditions and their probable consequences with the purely plausible outcomes of experiences that are merely potential. Second, it shows how the cognitive needs served in this way by both literature and pragmatic philosophy converge around a double truth. Just as we need forms to express and experience what would otherwise go unsaid and thus unfelt and unknown, so we also need forms that also help us retrieve what we have already experienced or understood but have then either forgotten or suppressed. Literary and philosophical forms serve both these functions by at once taking us out of ourselves to experience what is strange and foreign on the peripheries of our understanding and also return us to the center of our experience where we so often recover a sense of the strangeness and foreignness that is already within it. Third, this article discusses how these strategies have found expression in a tradition of American writing that begins with Emerson and continues down the present and is marked by a special kind of linguistic skepticism.
\end{abstract}

Keywords: philosophy, literature, pragmatism, John Dewey

The question that composes my title is intended to be a provocative. I want to see if I can dislodge some common assumptions both about pragmatism and about literature. I want to do this by an argument that has three loosely interrelated parts. The first takes up the issue of what, despite appearances, philosophical pragmatism and fictive forms have in common as methods of inquiry, modes of understanding. The second moves on to consider what sorts of cognitive needs they serve and how they satisfy them. The third then turns on how pragmatism has found expression in American writing and the ways it can be read. These various steps won't bring us to a single definition of what a pragmatist approach to literature might look like but it will, I hope, trouble those who might otherwise believe that this is merely an exercise in comparing apples and oranges.

When most of us use the word 'pragmatism,' we rarely have in mind anything that could be associated with the world of the arts. For most people, pragmatism refers to an attitude toward reality, an approach to problem-solving, which is practical, matterof-fact, hard-nosed, and results-oriented. The arts, on the other hand, are typically conceived of as imaginative, speculative, playful, and open-ended. Even if we know that as a philosophical perspective and method, pragmatism was developed by 
William James as a technique for resolving the otherwise interminable disputes between philosophers and other thinkers who were always getting hung up over first principles, apriori reasons, and fixed categories, we probably don't know that it was always intended to be an intellectual instrument that accords a significant place to the imagination.

Adapting some ideas of his colleague Charles Saunders Pierce, James defined pragmatism a theory of inquiry that included a particular conception of truth and a specific method for determining it. As for the method, James proposed that the meaning of any proposition was not necessarily confined to some particular to which it was alleged to directly point but should be expanded to include what within experience would have to change it if were held to be true. As to the theory, James argued that it would make better sense to think of the true less as some inherent property of ideas, such as their correspondence with reality, than as a feature of their working relationship with other parts of our experience.

In this slightly wooden epistemological formula, James was intending to offer a simple, common-sense rule for determining what beliefs actually amount to and how they become verified, but he actually accomplished a good deal more than this. In two bold strokes, James had taken epistemological operations out of the hands of the abstractly rational or the empirically measurable and recast them as more of an art than a science in which the 'inferential' and the 'possible' play at least as a significant a role in most forms of reflection as the 'practicable' or the 'verifiable.'

But how did he do this? How did James put the imagination back into a philosophical approach designed to shift the determination of the meaning and truth of ideas away from initial presuppositions, deductive reasoning, and closed arguments toward outcomes, consequences, and implications without simply reducing them crudely to their effects, to the differences they make? The answer is that if James associated the meaning of ideas in part, but only in part, with would have to change if they were true, he also realized that many of these supposed outcomes and consequences cannot be verified or corroborated before we must act on them. Hence he concluded that we act in general not on the basis of assured facts or validated predictions but on the basis of surmises, conjectures, and speculations. Thinking for James was something like "constructing an image of the environment, running the model faster than the environment, and then predicting that the environment will behave as the model does" (E. Egalanter and M. Gerstenhaber, quoted in Geertz 1973: 78). Thus for James the imagination assumes a role in the operations of the intellect that is far from accidental or merely secondary, since so much of the life of the mind is devoted to determinations whose results we can never substantiate in advance but can only guess at or gamble on before we have to respond to them.

John Dewey, James's philosophical ally, then took this same belief in the imaginative dimension of all epistemological operations one step further by identifying the intellectual, by which Dewey meant the critical, with a double movement that operates aesthetically in two directions at the same time. While one of 42 
the aesthetic movements of critical reflection inevitably carries inquiry back into the past to determine the probable, as opposed to demonstrable, conditions from which something presumably emerges, the second inevitably carries inquiry forward by trying to figure out the potential, as opposed to the unequivocally predictable or assured, results in which something may issue.

But Dewey didn't stop there. Indeed, his investigations into the place of the aesthetic in all acts of intellectual reflection convinced him that the aesthetic is not merely one category among others but, in fact, the potential form and destiny of every experience, the most basic category of all. Dewey had already stated as early as 1920 that philosophy needs to relinquish the search for an absolute and immutable reality and replace it with the effort to enhance all experience by exploring its possibilities for richer and more extensive fulfilment. This conviction eventually led him to reconceive experience itself as a form of art--as something that moves through resistances toward richer integrations--and then to reformulate the purpose of art as the continuous revaluation and augmentation of life itself. But by this time Dewey was also prepared assert that art is more moral than moralities. Moralities, he argued, merely consecrate the status quo, reinforce the established order. Art, by contrast, challenges the status quo and destabilizes the establish order by "keeping alive the sense of purposes that outrun evidence and of meanings that transcend [petrified] habit." (Dewey [1934] 1980: 348). In other words, the moral function of art was for Dewey identical with its critical function: "to remove prejudice, do away with the scales that keep the eye from seeing, tear away the veils of want and custom, perfect the power to perceive" (Dewey [1934] 1980: 325).

So much, then, for pragmatism's supposed indifference to art, its presumed incompatibility with fictive forms. But we can go further than this. Both literature and pragmatism seem to rely on the relation between the actual and the imagined, between the assumed or known and the possible, for whatever cognitive insights they can provide in the first place. Dewey put it best when he argued that the purpose of art is nothing less than to contrast actual conditions and their probable consequences with the purely plausible outcomes of experiences that are merely potential. But why do we do we need to submit to this exercise, you might ask? Because, as Dewey wrote, "it is by a sense of possibilities opening before us that we become aware of constrictions that hem us in and of burdens that oppress" (Dewey [1934] 1980: 346). So, literature and the other arts, we could say, serve important cognitive needs, particularly since these needs typically deal with elements of experience, with dimensions of life and understanding, that are often hidden from view and therefore difficult to detect. But what, more specifically, are these elements and dimensions, and how does, or may, a pragmatist approach to literature help bring them into focus?

Let's begin with the fact that, on the one hand, human beings, can never express or communicate everything they know, or feel, or want to share. The problem isn't simply that people are naturally defensive, or indifferent, or evasive (though I suspect that all of us are all of these thing at least some of the time), but rather that the 
motives, the reasons, the necessities for expression are often far more plentiful, often more problematic, than the opportunities for it. We all need to talk and be talked to, to tell our stories about the trip to the grocery, the date with our new heartthrob, the truth about the Economic Recession of 2008, but our society can never adequately provide us with sufficient opportunity for such conversations for any number of reasons: because the saying of it would expose us to contempt, hostility, danger, incrimination, or embarrassment; or because the persons with whom we would and must speak are, like dead relatives, absent friends, estranged lovers, singing nightingales, or divine beings inaccessible to us; or because what we have to say is too complicated, subtle, elusive, ambiguous, or offensive for any social exchange to accommodate.

Consequently, there are always sentiments we would like to express, knowledge we could acquire, ways we might wish to speak, but for the fact that there are either no suitable occasions on which to do so, or no acceptable audiences to hear it, or no style or idiom or terms in which to say it. What literary texts, like other fictive forms, do is to create such occasions, to define such audiences, to develop such necessary styles. The poem, the novel, the play, the essay furnishes us with a situation where conversations with lovers, or with God, or with the dead, or with flowers, can and, in effect, do occur, but they occur obliquely, circuitously, sometimes deviously. Since the writer can't bring the dead back to life, or make God visible, or restore the beloved to the lover, she must instead invent or re-present situations where lovers, God, or the dead, can speak and be responded to, can be interacted with. Thus the writer seeks to tell "all the truth," as the America poet Emily Dickinson once said, but must "tell it slant."

Works of art, stories, tales, narratives serve our practical cognitive needs, that is, help us know things we need to know, by providing us with new expressive powers, by allowing us to speak, as it were, the otherwise unspeakable. But works of art and literature also serve our additional practical need, again cognitive, to recover and recognize what, in truth, we may have already partially experienced but then have either forgotten or for some reason suppressed. This forgetting and suppressing and, to use the psychoanalytic word, repressing occurs all the time because each of us is the subject of far more experiences than we can possibly absorb, much less assimilate. Given the practical demands on ordinary perception, we simply cannot give equal attention to all the things that impinge on us either from the external world or from the world of our own conscious and unconscious. In truth, our ordinary perceptions are so fully focused on--and so fully delimited by--the demands of the immediate situation that we rarely succeed in remembering for very long any experiences but those that serve our most obvious and immediate cognitive needs. As a result, much that happens to us, and thus that is potentially knowable by us, slips by seemingly unknown or in any case unacknowledged.

Hence, again, our practical need for some instrumentality, some mechanism, that will allow us to retrieve such forgotten or suppressed experiences so that we don't lose them altogether. This is the second thing that narratives, stories, literary texts are 44 
designed in part to do: to help us remember what very often we didn't even know we knew -"a perception never before quite articulated, an emotion we had sustained on the periphery of consciousness, a sense, barely grasped, of the import of some incident" (Smith 1978: 145). Narratives, lyrics, dramas, and other forms help us not only hold on to these experiences but actually recover them by constructing textual situations or contexts which present us with some new reasons to attend to them and take them seriously.

So let us review for a moment. One of the practical cognitive needs that narratives, stories, and tales, like music, visual art, film, and the built environments, all serve is provide opportunities to imagine the inconceivable, think the unthinkable, say the unsayable, hear the unhearable, feel the unfeelable. At the same time, they also help us to recover parts of our experience that we would otherwise have lost. In this sense, they not only take us out of ourselves to experience foreign territories of experience but they also return us to ourselves to recover the sense of the strangenesses we did not know we knew.

But works of art also deal with elements of life that are sometimes painful and ambiguous and sometimes threatening as well as fascinating, so how do they capture and hold our attention? What is it about them as forms of experience that permits them to override our usual impatience with complexity and our usual intolerance of discomfort? One reason is our interest in suspense. We like to see how things turn out, even if the things themselves are not very interesting to us. So we refuse to switch channels to leave a very dull or stupid program on television if our curiosity about its outcome is aroused. This is part of our desire for closure, for completion, for resolution, that goes very deep in all of us and that most of us can't live without a sense of for very long.

The second reason that we are compelled to take certain works of literature seriously has to do with their relation to feeling. They arouse and stimulate feelings, to be sure, but they also operate of means of feeling. As William Butler Yeats once put it, works of art do their thinking "in the mire and fury of human veins." Far from merely evoking emotion in the reader, which is true in itself and no doubt likewise valuable, narratives and the other arts also embody in themselves models, paradigms, images of what for their audiences feeling or affect actually is. That is, they represent forms by which to feel with when the truth of experience is not a matter of meanings and ideas but of senses, intimations, intuitions, divinations, suppositions, superstitions. Hence Marcel Proust's claim that certain truths can only be examined and expressed in the form of stories.

Third and finally, fictive forms hold our attention, even when they force us to confront disquieting realities and truths, because they are constructed like 'as-if' statements, or what in philosophy are called 'conditional contrary-to-fact statements.'

\footnotetext{
${ }^{1}$ For Smith's entire discussion of the cognitive needs theory, see Smith (1978: 145-46).
} 
That is, artistic forms, and the actions or events they represent, are structured not as logics of probability but as logics of plausibility; what they ask us to entertain is not that the situations they develop within their confines might happen but could happen. In other words, works of art invite us to grant them their initial assumptions, assumptions we can all accept as either more or less 'givens' in life or potential to it in Shakespeare's King Lear, that all fathers want a measure of gratitude from their children; in Harriet Beecher Stowe's Uncle Tom's Cabin, that all mothers want to keep their families together; in Nathaniel Hawthorne's The Scarlet Letter, that all lovers deserve to be reunited and all children deserve to be acknowledged by their parents; in Herman Melville's novel Moby-Dick, that cosmic injustice has to be answered for - and then proceed to show where, under certain selected conditions, those assumptions can lead.

Works of art are thus suppositional or conjectural structures, structures we can attend to even when they disturb us because they are designed to tell us not what did, or always does, or inevitably must, happen in life, but rather what could happen if life were shaped as perfectly by forms and styles of feeling as Don Quixote or Remembrance of Time's Past. What the work of art takes from life are not its conclusions but rather the terms and substance of its original premise. It then selects, organizes, and motivates that premise - all father's want gratitude from their children, all mothers want to keep their families together, etc. - In a such a way as to produce a purely hypothetical set of events that are not given at all but that nonetheless follow credibly from it as a series of potentialities inherent in a set of actualities.

Works of art are thus constructed more like laboratory experiments than like philosophical arguments; that is, they are like hypotheses in need of validation, not like propositions in need of verification. And from this it follows that the purpose of art is less to confirm or interpret the known than to explore unknown, to induce us to think that something else might be, or at least could be, the case. To put this another way, it is "to enable us to think and feel otherwise than as we do. It is to erect a larger context of experience within which we may define and understand our own by attending to the disparity between it and the experience of others" (Cunningham 1960: 141).

In this conception, then, the heuristic or educational value of the aesthetic is closely associated with its pragmatics, and its pragmatics are both critical and emancipatory. Aesthetic texts are critical because they seem to emerge at that point where, as Hayden White once put it, "our apprehension of the world outstrips our capacities for comprehending it, or, conversely, where canonized modes of comprehension have closed off our capacities for new experience." Those we at least tend to value most highly seem to breach, to return to White, "the conventional hierarchies of significance in which experience is presently ordered" and to project a new imagination or sense of things "which previously existed only as a perceptual possibility" (White 1970: 179-80). On the other hand, imaginative texts are potentially emancipatory just insofar as the contrast they probe, or at any rate 46 
presuppose, between the actual and the potential leads to an extension, however minimal, of our sense of the knowable. To read them this way is to read them 'pragmatically' - in relation to the act of a mind as it feels, as much as thinks, its way through words toward the circumstances of their affective significance in consciousness.

This is the way reading was taught, Richard Poirier argued, in a famous undergraduate course at Harvard in the mid-fifties and early sixties known as 'Hum 6,' a course that took its inspiration from Ralph Waldo Emerson's famous declaration that "the poet uses forms according to the life, and not according to the form." Emerson's statement has frequently been taken to license a vaporous, diffuse, unstructured subjectivity of which Emerson himself has often been held to be guilty, but Poirier believes that this statement repositions Emerson as the source of a tradition of literary and intellectual pragmatism in American writing that constitutes an alternative to the conventional view of modernism and casts modernism's relation to postmodernism in an entirely different light. Defining a group of writers originating with Emerson and including Whitman, the James brothers, Frost, Stein, and Stevens, while conceding a place as well to a host of other writers from Thoreau, Dickinson, Pound, and Dewey to William Carlos Williams, Kenneth Burke, John Ashbery, and A. R. Ammons, this was, and is, a tradition held together chiefly by its aversion to absolutes and foundationalism, its fascination with contingency, process, and change, its respect for the commonplace and the ordinary, its belief in the constructed nature of truth, and its emphasis on the relational dimensions of the real.

This is a tradition has expressed itself typically in one of two ways or modes. The first might be thought of as 'comic' because it exhibits a wary but often bemused, if not humorous, skepticism toward anything that can be identified with what the sociologist Peter Berger once called "the noise of solemn assemblies." Assuming that in an economy of moral and intellectual scarcity cultural forms will always rush in to fill the vacuum by encouraging the development of a certain moral pretentiousness, what Kenneth Burke would describe as an attitude of 'Holier than Thou,' the comic or vernacular strain in American pragmatism typically attempts to resist the pull of cultural pieties by rhetorically negotiating a kind of transcendence downward in order to restore what, in Armies of the Night, Norman Mailer described as "the hard edge of proportion to the overblown values that otherwise threaten to engulf each small military existence." (1968: 47). In its antic or playful dimensions, then, this pragmatist tradition of writing tends to view "the world's rich store of error as a genuine aspect of truth," to quote Kenneth Burke, and therefore urges us, to continue with Burke, because "the troublous genius of symbolism," is always tempting us to misjudge and inflate reality, to spy on ourselves with "pious yet sportive fearfulness" Rueckert (1982: 161).

In its more elevated or at least less antic form, on the other hand, this same pragmatic tradition has found its own richest intensifications by exploring moments when the ordinary becomes exceptional, the familiar strange, the habitual other 
without at the same time being made available either to the reductionisms or to the bloatings of ideology. These are moments when the actual is rendered extraordinary, the prosaic mysterious, the commonplace sublime because it is imagined "as if it were not less but, because extemporized within and also against existent forms, immeasurably more than the result of some 'arrangements of knowledge." (Poirier 1987: 202). Here rhetoric seeks not to deflate, subvert, exaggerate, or ridicule the subjects of its discourse but to submit the tropological behavior of language itself to the energies of its own verbal technologies. In the moment when punning, joking, and troping break the grip of institutionalized terminologies, a kind of self-emancipation is effected merely by the way the writing calls attention to the performative presence of a self even in gestures of its own dissolution or self-effacement.

Poirier was at first tempted to call this literary practice of pragmatist self-erasure a kind of 'writing off the self' (Poirier 1987: 181-223). But he later reconceived it as a self-conscious linguistic skepticism, where the arrow of sense released by the deconstructive mechanisms within language itself actually enable language to point beyond skepticism, toward possibilities for personal and cultural renewal. To follow this movement within language beyond language requires, it is necessary, Poirier insisted, to think differently about words and the things that can be done with them. Where the conventional way of thinking about such matters associates words with things, language with reference, and verbal signs with substantives, Emerson, anticipating the nomenclature that William James would later employ to give this linguistic skepticism its first American philosophical elaboration, was convinced that words have more to do with actions and events, language with processes and power, verbal signs with transitives and connectives.

James formulated this possibility most simply when he said somewhere that what "[verbal] formulas express leaves unexpressed almost everything that they organically divine and feel." It is this element of the 'unexpressed' and the verbally inexpressible-what James simply called "the vague" and its cognate "the superfluous" - that a pragmatic perspective brings back into criticism, just as James before him wanted to reinstate it in philosophy. Vagueness is an interpretive consequence of that excess of intelligibility that accompanies every act of perception, a "Sense of the More," as James described it, attendant upon all acts of understanding and constitutes the remainder that is always left over when we try to calculate the interpretive sum, so to speak, yielded by such acts. Vagueness, ambiguity, even undecidability, derive from the failures that language continuously experiences in its effort to represent its own understanding in words. But this failure is quickening as well as salutary. The words are there to point to, or, better, lead toward insights, intuitions, intimations that would be lost if in fact they were named.

Here, then, is where the pragmatic approach to literature is, or can be, particularly illuminating. By showing how purposes in literary texts, indeed all works of art, often outrun evidence and meanings transcend reference, it not only reveals how such texts imaginatively work but helps account for the sources of their spell. 


\section{REFERENCES}

Dewey, John (1980). Art as Experience (1934). New York: Perigee Books.

Geertz, Clifford (1973). The Interpretation of Cultures. New York: Basic Books.

Cunningham, J. V. (1960). Tradition and Poetic Structure. Denver: Alan Swallow.

Mailer, Norman (1968). Armies of the Night. New York: New American Library.

Poirier, Richard (1987). The Renewal of Literature: Emersonian Reflections. New York: Random House.

Rueckert, William H. (1982). Kenneth Burke and the Drama of Human Relations (1963). Berkeley: University of California Press.

Smith, Barbara Herrnstein (1978). On the Margins of Discourse. Chicago: University of Chicago Press.

White, Hayden (1970). The Point of It All. New Literary History 2: 179-80. 